\title{
Estado actual, retos y algunos aportes de la investigación en el estudio de la tuberculosis
}

Current state, challenges and some research support in the tuberculosis

study.

\author{
Carlos Yesid Soto Ospina, PhD
}

Departamento de Química, Universidad Nacional de Colombia

Director del Grupo de Bioquímica y Biología Molecular de las Micobacterias

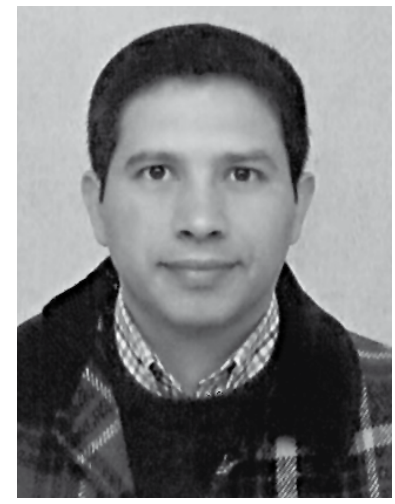

T a tuberculosis (TB) es una de las enfermedades infecciosas que causa el mayor número de muertes. Aproximadamente dos mil millones de 1 personas se encuentra infectadas por Mycobacterium tuberculosis, una micobacteria que cada año produce cerca de ocho millones de nuevos casos de TB y dos millones de muertes al rededor del mundo. En las últimas décadas la incidencia de las infecciones producidas por micobacterias ha aumentado de forma dramática, en especial las causadas por M. tuberculosis. La Organización Mundial de la Salud, en su informe anual del 2006 alerta que a pesar de los avances realizados a nivel global para controlar las infecciones causada por micobacterias, su incidencia continúa aumentando, y la considera junto con la malaria y el SIDA como las denominadas "enfermedades ligadas a la pobreza". El diseño de una nueva vacuna más eficiente que la actual BCG, el desarrollo de métodos de diagnóstico rápido, la búsqueda de nuevos agentes antituberculosos y el control de la TB latente son las prioridades actuales de la investigación en este campo.

En Colombia las infecciones por micobacterias se consideran un importante problema de salud pública. El informe del Instituto Nacional de Salud de 2006, "Vigilancia de la Resistencia de Mycobacterium tuberculosis a los Medicamentos. Colombia 2004-2005”, alerta sobre un incremento sostenido de la TB en Colombia a partir del año 1997. Para el 2005 la tasa de incidencia se valoró en 22 casos por 100.000 habitantes, pero desafortunadamente existe un alto subregistro por lo que supondría que en nuestro país la incidencia de TB podría realmente alcanzar hasta 53 casos por 100.000 habitantes. La incidencia de las infecciones por micobacterias se incrementa principalmente por la coinfección con el virus de inmunodeficiencia humana (VIH), la aparición de cepas de micobacterias resistentes a los compuestos antituberculosos, en especial las extremadamente resistentes (XDR) y la TB latente. En Colombia en el año 2008 se reportó el primer caso de TB causado por la cepa XDR Beijing, que ha producido graves epidemias en muchos de los países que se ha detectado, lo que sitúa al país en alerta sanitaria frente a la TB multiresistente.

Aproximadamente solo un 10\% de las personas infectadas de TB desarrollan la enfermedad, permaneciendo la micobacteria en estado latente en el resto de la población. Anualmente entre el 8-10\% de la población con infección latente desarrolla TB activa debido principalmente a la coinfección con VIH. En la actualidad se conoce muy poco sobre la fisiología y los mecanismos moleculares relacionados con el metabolismo del bacilo latente, su capacidad para neutralizar la acción de los agentes quimioterapeúticos, la naturaleza de su regulación 
genética, así como la interacción hospedero-patógeno que permite su persistencia en la lesión tuberculosa o granuloma. Se han observado importantes alteraciones en la microestructura de la pared celular y en la tinción de Ziehl-Neelsen de las micobacterias latentes, que sugieren posibles cambios en la composición lipídica de la pared celular, incluidos glicolípidos, que tienen un papel relevante en la modulación de la respuesta inmune y en la virulencia de las micobacterias. Los análisis genómicos han mostrado una variedad de genes relacionados con la entrada de la micobacteria al estado latente, entre ellos dos un regulador trascripcional global que se sobreexpresa en condiciones experimentales de latencia.

El tratamiento contra la TB consiste básicamente en una combinación de fármacos que utilizados de forma correcta controlan la enfermedad. Sin embargo, el abandono del mismo por parte de los pacientes, las fallas en el suministro y calidad de los antibióticos durante su prolongada duración, han propiciado la aparición de cepas de micobacteria resistentes a los antibióticos. Entre las micobacterias, incluidos los patógenos humanos $M$. tuberculosis y el oportunista $M$. avium, existe un elevado porcentaje de cepas que presenta resistencia a los antibióticos. El nivel de resistencia que presentan las micobacterias depende de factores fisiológicos como el estado de aerobiosis o anaerobiosis, factores genéticos como la adquisición horizontal de genes de resistencia, mutaciones, etc. que constituyen la denominada resistencia adquirida; y finalmente la resistencia intrínseca, innata, o natural. Esta última incluye la barrera de permeabilidad formada por la muy hidrofóbica pared celular de las micobacterias, los mecanismos de resistencia endógenos mediados por las bombas de eflujo, y cualquier otro mecanismo que confiera un nivel de resistencia basal frente a los antibióticos.

En la actualidad el fenómeno de cepas de $M$. tuberculosis extremadamente resistente a los antibióticos (XDR-TB) obliga al diseño de nuevos fármacos, de lo contrario las opciones clínicas de tratamiento serán muy limitadas en el futuro. Tampoco existen fármacos amables para controlar la TB latente. La búsqueda de nuevas alternativas terapéuticas para el control de la TB requiere el conocimiento de nuevas dianas celulares esenciales y el entendimiento de sus mecanismos de acción. Este objetivo implica conocer las bases moleculares, la evolución y diseminación de la resistencia, la persistencia y la latencia las micobacterias, lo que facilitaría el diseño de nuevos fármacos efectivos para controlar las diferentes formas de infección tuberculosa.

Actualmente el grupo de Bioquímica y Biología Molecular de las Micobacterias (BBMM) de la Universidad Nacional de Colombia contribuye al estudio de los mecanismos moleculares relacionados con la infección y diagnóstico de las micobacterias. La aproximación experimental desarrollada por nuestro grupo de investigación consiste básicamente en el estudio de componentes genéticos y estructurales relacionados con la latencia de las micobacterias, la búsqueda de nuevas dianas terapéuticas, evaluación de nuevos antituberculosos y el estudio de los mecanismos de resistencia de las micobacterias a los antibióticos. Respecto al diagnóstico nuestro trabajo se ha enfocado en el desarrollo de un método para detectar y diferenciar Mycobacterium colombiense, una micobacteria no tuberculosa perteneciente al complejo $M$. avium (MAC) la que está relacionada con una alta incidencia de infección en pacientes son SIDA en Bogotá. Hasta el momento no existe un método de diagnóstico rápido y fácil para diferenciar $M$. colombiense de las demás micobacterias del MAC, el que podría ser aplicado en pacientes con sospecha de micobacteriosis en nuestro país. 
En el estudio de nuevos antituberculosos el grupo investiga en la potencial utilidad de péptidos antibióticos para el control de las micobacterias. El resultado de nuestras investigaciones ha mostrado que algunos péptidos de respuesta innata de diferentes organismos poseen actividad antimicobacteriana. En la actualidad estudiamos el mecanismo de acción de estos péptidos contra las micobacterias, y en un futuro utilizar la ingeniería de péptidos para incrementar su actividad. Por otra parte, también investigamos la búsqueda de nuevas dianas terapéuticas. Estudiamos enzimas relacionadas con la homeostasis celular como posibles blancos terapéuticos para el diseño y/o búsqueda de nuevos compuestos antituberculosos.

En el estudio de la infección latente trabajamos en la búsqueda de marcadores lipídicos de la pared micobacteriana asociados a condiciones experimentales de latencia. La idea es relacionar las variaciones estructurales de la micobacteria hipóxica, forma experimental de latencia, con antígenos que caractericen las bacterias latentes. Utilizando técnicas cromatográficas hemos encontrado variaciones en el contenido glicolipídico de M. tuberculosis crecido en condiciones de hipoxia respecto a bacterias crecidas en completa aireación, lo que sugiere posibles cambios estructurales en la pared celular y en la virulencia de las micobacterias en condiciones experimentales de latencia. La identificación de componentes estructurales asociados al estado latente de las micobacterias ayudaría a conocer los mecanismos utilizados por $M$. tuberculosis para persistir en las lesiones tuberculosas y hacerse invisible al sistema inmune. Los marcadores lipídicos relacionados a las micobacterias latentes podrían ser utilizados para desarrollar estrategias encaminadas a estimular el sistema inmune y de esta forma lograr combatir de una manera más efectiva la infección latente por micobacterias.

Para finalizar, los esfuerzos en salud pública y en la investigación clínica y básica relacionada con las infecciones causadas especialmente por $M$. tuberculosis, redundarán en el bienestar de las comunidades afectadas, las que se concentran principalmente en países en vías de desarrollo como el nuestro, en los que todavía se requiere de mucho trabajo para el control de la TB y en general de las infecciones causadas por micobacterias. 